\title{
T-Cell Lymphoma Presenting With Bilateral Chylothorax
}

\author{
Ibrahim Ethem Ozsoy and Mehmet Akif Tezcan \\ Department of Thoracis Surgery, Kayseri City Hospital, Molu Kocasinan Kayseri, Turkey
}

\begin{abstract}
Chylothorax is the accumulation of chyle in the pleural cavity due to obstruction or injury arising in the thoracic duct or its large branches. In more than $50 \%$ of patients diagnosed with chylothorax, the etiology consists of malignant diseases; and among these, lymphomas are the most common cause, accounting for $60 \%$ of cases. We report a case of a 37 -year male with T-cell lymphoma who presented with bilateral pleural effusion; pleural fluid analysis confirmed chylothorax. A solid lymph node was detected in the left zone 4 on neck ultrasonography. Tru-cut biopsy was done and reported as T-cell lymphoma. The cytology was consistent with Class V (Malignant) T-cell lymphoma infiltration. Bilateral chylothorax, a complication of T-cell lymphoma, is a rare presentation of this disease. Our patient was diagnosed rapidly with both chylothorax and lymphoma. We started the treatment immediately and saved his life.
\end{abstract}

Key Words: Chyle, Chylothorax, Lymphoma.

How to cite this article: Ozsoy IE, Tezcan MA. T-Cell Lymphoma Presenting With Bilateral Chylothorax. J Coll Physicians Surg Pak 2020; 30(11):1220-1222.

\section{INTRODUCTION}

Chylothorax is the accumulation of chyle in the pleural cavity due to obstruction or injury arising in the thoracic duct or its large branches. ${ }^{1}$ The first record of the lymphatic system goes back to Hippocrates (460-370 BC), who mentioned white blood in the axillary lymph nodes and coined the word "chyle". Aristotle (390-320 BC) described the lymphatic system as a white blood vessel. ${ }^{2}$ In more than $50 \%$ of patients diagnosed with chylothorax, the etiology consists of malignant diseases; and among these, lymphomas are the most common cause $(60 \%)$. In lymphomas, chylothorax occurs when the tumor directly invades the duct, or lymph node or a tumor embolism occludes the duct. Chylothorax may be bilateral or unilateral, depending on the location of the tumor and stasis. ${ }^{3}$

We present a case of chylothorax as the patient presented with bilateral pleural effusion and was diagnosed with T-cell lymphoma.

\section{CASE REPORT}

A 37-year male was admitted to the Emergency Department with dyspnea. He had no other remarkable history of disease, transfusion, or medication.

Correspondence to: Dr. Ibrahim Ethem Ozsoy, Department of Thoracis Surgery, Kayseri City Hospital, Molu Kocasinan Kayseri, Turkey

E-mail: ibrahimethem.ozsoy@sbu.edu.tr

Received: August 23, 2019; Revised: October 31, 2019;

Accepted: November 10, 2019

DOI: https://doi.org/10.29271/jcpsp.2020.11.1220

Upon physical examination, the patient was hemodynamically stable and had good oxygen saturation. There was hard, fixed $4 \times 3 \mathrm{~cm}$ lymph node in the left supraclavicular region. His vesicular sounds were decreased on chest auscultation. Laboratory examination demonstrated increased leukocyte count $\left(23.6 \times 10^{3}-/-\mu \mathrm{L}\right)$. Chest X-ray showed bilateral pleural fluid, more prominent on the right side. Thoracic computed tomography showed multiple lymph nodes located in the paravertebral and paratracheal regions in the mediastinum, bilateral pleural effusion, perisplenic and perihepatic fluid and paraaortic, paracaval, conglomerated lymph nodes (Figure 1). Bilateral pleural effusion samples appeared whitish in colour (Figure 2 ). In the right-sided pleural fluid sample, the number of leukocytes was 7,960, with $82 \%$ lymphocytes. Its glucose, protein, lactic dehydrogenase (LDH), cholesterol, and triglycerides were $107 \mathrm{mg} / \mathrm{dL}, 39.7 \mathrm{~g} / \mathrm{L}, 220 \mathrm{U} / \mathrm{L}, 53 \mathrm{mg} / \mathrm{dL}$ and $343 \mathrm{mg} / \mathrm{dL}$, respectively. In the left-sided pleural fluid sample, the number of leukocytes was 8,020 , with $80 \%$ lymphocytes. Its glucose, protein, $\mathrm{LDH}$, cholesterol and triglycerides were $115 \mathrm{mg} / \mathrm{dL}$, $36.3 \mathrm{~g} / \mathrm{L}, 240 \mathrm{U} / \mathrm{L}, 75 \mathrm{mg} / \mathrm{dL}$ and $220 \mathrm{mg} / \mathrm{dL}$, respectively. Pleural fluid collected from both sides was exudative according to Light criteria. Ziehl-Neelsen staining was negative and there was no growth on culture. The cytology was consistent with Class V (Malignant) T-cell lymphoma. The patient underwent bilateral catheter thoracostomy. Around 2,400 $\mathrm{ml}$ and $1,600 \mathrm{ml}$ of chylous fluid was drained from the right and left sides, respectively. Oral intake was discontinued and total parenteral nutrition (TPN) was started. TPN was prepared by calculating the water, energy and amino acid needs of the patient. Neck ultrasonography was performed and a solid lymph node $46 \times 30 \mathrm{~mm}$ was detected in the left zone 4 . A tru-cut biopsy was performed, which was reported as T-cell lymphoma. 


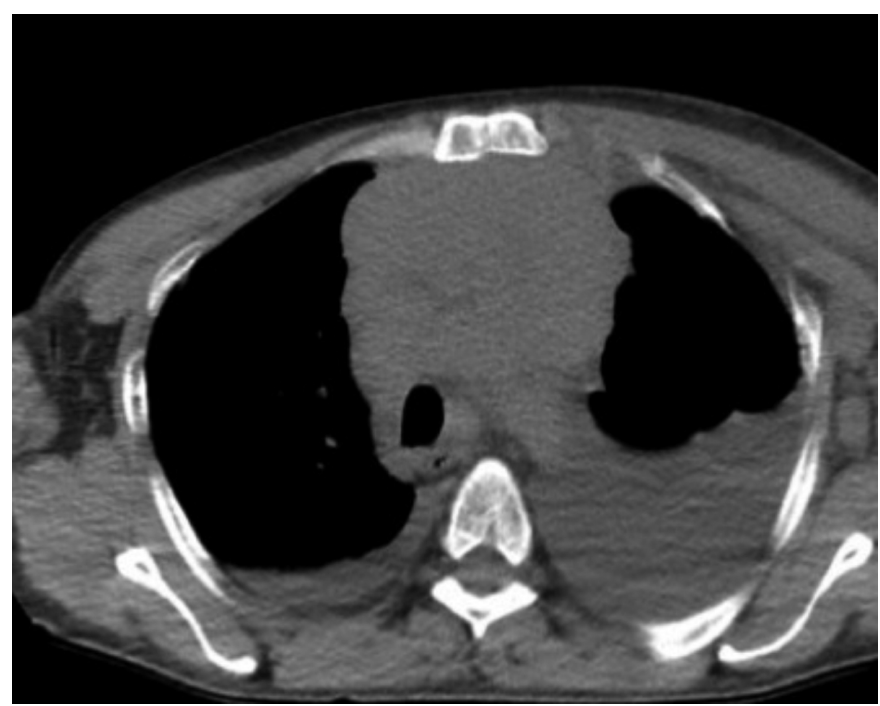

Figure 1: Computed tomography of the chest showing bilateral pleural effusion and mediastinal lymphadenopathy.

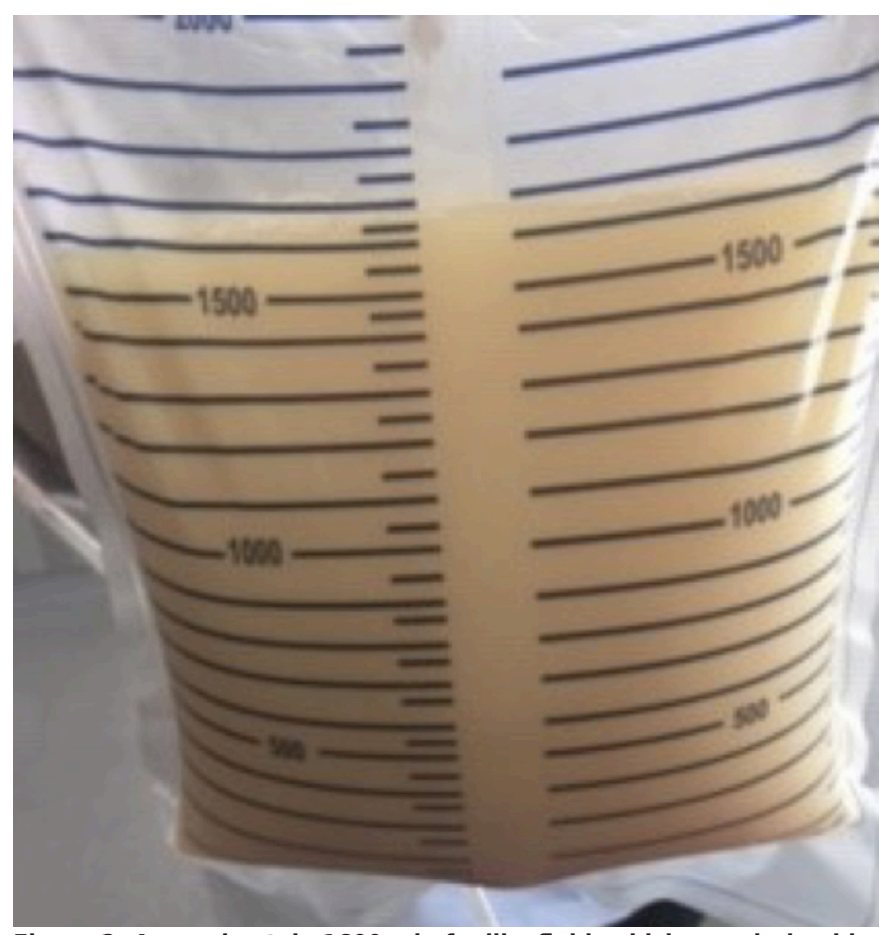

Figure 2: Approximately $1600 \mathrm{ml}$ of milky fluid, which was drained by catheterthoracostomy.

CHOP (cyclophosphamide, doxorubicin, oncovin and prednisolone) chemotherapy was given to the patient. Amount of chyle drainage did notreduce despitechemotherapy. Daily drainage was 1,100 to $1,300 \mathrm{ml}$ on both sides. Patient received somatostatin treatment for 6 days. After fluid drainage fell below $100 \mathrm{ml}$, catheter thoracostomy was discontinued. The patient was discharged on the $29^{\text {th }}$ day in stable condition.

\section{DISCUSSION}

Chylothorax is one of the rare but most serious causes of pleural effusion. The most common classification for the etiology of chylothorax is the one proposed by Bessone et al. in 1971; and according to this classification, diagnostic procedures, tumors, and the congenital, traumatic, and idiopathic factors are among causes of chylothorax. ${ }^{4}$

Lymphomas are responsible for $10 \%$ of malignant pleural effusions or ascites, which can be observed in $20-30 \%$ of all types of lymphomas during their clinical courses. The lymphomas are the most important cause of spontaneous chylothorax. Lymphoma-associated pleural fluid is often linked with lymphadenopathy, which can be monitored on thoracic computed tomography. Cytology might be positive at the rate of $40 \%$. Chylothorax can be observed in lymphomas at the rate of $15 .{ }^{5}$ The mechanism for the formation of chylothorax, caused by tumors, is the direct damage to or the neoplastic obstruction of ductus thoracicus, which leads to the rupture of the thoracic duct itself or its branches. Unilateral or bilateral chylothorax, may occur in these cases. ${ }^{6}$

Most of the patients with chylothorax are asymptomatic, but shortness of breath (SOB) and cough may develop as the amount of fluid accumulation the intrapleural space increases. Infective findings are not common due to the bacteriostatic effect of fatty acids and lecithin, which abound in the chylous fluid. This fluid is non-irritant. Therefore, it does not cause chest pain. ${ }^{7}$ Our patient was admitted to the hospital due to SOB and not chest pain.

Diagnosis of chylothorax is made by the analysis of pleural fluid. The sample taken from pleural fluid should be subjected to Gram staining, protein and triglyceride and cholesterol screening test and cell counts. Triglyceride levels above 110 $\mathrm{mg} / \mathrm{dL}$ are most diagnostic scale for chylothorax. A cholesterol/triglyceride ratio less than 1 is also diagnostic. Although chylothorax is not radiologically different from other pleural effusions, it may cause compression atelectasis and mediastinal displacement. ${ }^{3}$

Differential diagnosis includes empyema. In empyema analysis, the dominant cells are polymorph leukocytes; whereas, the chylous fluid contains lymphocytes. White fluid accumulation is sometimes seen in empyema cases, as well. The chylous fluid becomes clear when treated with ether; whereas, empyema remains unchanged. The chylous fluid stains with Sudan Black B, but empyema fluid does not. Bacterial growth may occur in empyema fluid culture in contrast to chylothorax. ${ }^{3}$

Catheter thoracostomy or tube thoracostomy is first applied to the patient diagnosed with chylothorax, thereby allowing pulmonary re-expansion and correcting compressive atelectasis and mediastinal shift caused by chylous pleural fluid. Discontinuation of oral intake or removal of fatty acids, greater than 12 carbons from the oral diet, would both reduce the chylous leakage and decrease bowel secretions, thus minimising the loss of protein, fat, lymphocyte, and fluid. ${ }^{8}$ Somatostatin and its analogue, octreotide, are alternatively used in medical treatment. These drugs reduce the formation of chylous fluid by inhibiting the physiological functions that regulate the gastrointestinal tract and pancreas. ${ }^{9}$ If the daily drai- 
nage is less than $150 \mathrm{~mL}$ after two weeks of medical treatment and there is no increase in drainage with the continuation of oral intake, medical treatment is considered successful and chest drainage is terminated. There are reports showing that low-dose mediastinal radiotherapy is beneficial in surgical refractory cases. Malignant chylothorax may be treated with chemical pleurodesis, chemotherapy and radiotherapy. Talc pleurodesis may be an effective alternative. ${ }^{3}$

We first stopped the oral intake and started TPN. We drained the pleural fluid by performing catheter thoracostomy. Although our patient received CHOP chemotherapy for lymphoma treatment, chylous fluid drainage continued. Then, somatostatin treatment was administered to him for 6 days, and fluid drainage stopped. Thus, there was no need for pleurodesis.

If conservative treatment fails, surgical treatment should be sought. If the location of leakage is detected in surgery, it is essential to close the leakage with non-absorbable pledget sutures. However, mass ligation should be performed in cases where the location of the leakage cannot be determined exactly. The pleuro-peritoneal shunt may be constructed in patients who do not benefit. ${ }^{10}$

Bilateral chylothorax, a complication of T-cell lymphoma, is a rare presenting feature of this neoplasm. Early diagnosis and treatment can save the life of the patient, as in this case.

\section{PATIENT'S CONSENT:}

Informed consent is obtained from the patient.

\section{CONFLICT OF INTEREST:}

The authors declared no conflict of interest.

\section{AUTHORS' CONTRIBUTION:}

IEO: Concept, data collection and interpretation, literature search and manuscript writing.

MAT: Concept, data collection and interpretation

\section{REFERENCES}

1. Dubin PJ, Kind IN, Gallagher PG. Congenital chylothorax. Curr Opin Pediatr 2000; 12: 505-9.

2. Ceylan i. History. In: Ceylan I, Ed. Lymphatic system and diseases. Ankara: Turkish Surgical Society Publications 2016, pp. 5-7.

3. Koçer B. Chylothorax. In: Özyurtkan MO, Bostancı K, Özpolat B, Eds. Thoracic traumas. Ankara: Nobel Medical Publishers. 2018, pp. 261-74.

4. Bessone LN, Ferguson TB, Burford TH. Chylothorax: A collective review. Ann Thorac Surg 1971; 12:527.

5. Light RW. Pleural Diseases. Ed. $5^{\text {th }}$ Philadelphia: Wolter Kluwer, 2007.

6. O'Callaghan AM, Mead GM. Chylothorax in Iymphoma: Mechanisms and management. Ann Oncol 1995; 6(6):603-7.

7. McGrath EE, Blades Z, Anderson PB. Chylothorax: Aetiology, diagnosis and therapeutic options. Respir Med 2010; 104(1):1-8.

8. Çubuk S, Yücel O. Current overview of chylothorax. In: Yücel O, Ed. Surgical treatment of pleural diseases. Turkish respiratory society education book series. Istanbul. pp.106-113.

9. Demos NJ, Kozel J, Scerbo JE. Somatostatin in the treatment of chylothorax. Chest 2001; 119: 964-6.

10. Murphy MC, Newman BM, Rodgers BM. Pleuroperitoneal shunts in the management of persistent chylothorax. Ann Thorac Surg 1989; 48: 195-200. 